\title{
Docking Studies and Antiprotozoal Activity of Secondary Metabolites Isolated from Scrophularia syriaca Benth. Growing in Saudi Arabia
}

\author{
Abdulsalam A. M. Alkhaldi 1, Arafa Musa 2,3," Ehab M. Mostafa 2,3, \\ Elham Amin 4 and Harry P. De Koning 5 \\ ${ }^{1}$ Department of Biology, College of Science, Jouf University, Sakaka, 2014, Saudi Arabia \\ ${ }^{2}$ Department of Pharmacognosy, College of Pharmacy, Jouf University, 2014, Sakaka, Saudi Arabia \\ ${ }^{3}$ Department of Pharmacognosy, Faculty of Pharmacy, Al-Azhar University, Cairo, 11371, Egypt \\ ${ }^{4}$ Department of Pharmacognosy, Faculty of Pharmacy, Beni-Suef University, Beni Suef, 62514, \\ Egypt \\ ${ }^{5}$ Institute of Infection, Immunity and Inflammation, College of Medical, Veterinary and Life Sciences, \\ University of Glasgow, Glasgow G12 8TA, UK
}

(Received March 22, 2019; Revised May 09, 2019; Accepted May 10, 2019)

\begin{abstract}
Phytochemical study of the ethanolic extract of Scrophularia syriaca Benth. was attained by chromatographic and spectroscopic procedures, which resulted in the isolation of eight compounds; $6-O-\alpha-\mathrm{L}-$ rhamnopyranosylcatalpol (1), scropolioside B (2), gmelinoside-L (3), 8-acetyl harpagide (4), scropolioside D (5), scropolioside $\mathrm{D}_{2}(\mathbf{6})$, quercetin (7) and kaempferol-3-O-rutinoside (8). Their antiprotozoal activity was evaluated against Trypanosoma brucei brucei (s427-WT), Trypanosoma brucei brucei (TbAT1-B48), Leishmania major and Leishmania mexicana. Compounds 2, 5, 7 and $\mathbf{8}$ exhibited mild to moderate activities against kinetoplastid parasites compared to pentamidine positive control, the mechanism of antiprotozoal activity was investigated using molecular docking studies on the potential target enzyme Trypanosoma brucei glyceraldehyde-3-phosphate dehydrogenase (TbGAPDH).
\end{abstract}

Keywords: Scrophularia syriaca; docking; iridoids; Leishmania; Trypanosoma. @ 2019 ACG Publications. All rights reserved.

\section{Introduction}

Human infections with either Trypanosoma or Leishmania are common in several populations, from which the Africans suffer the highest disease burden. Transmission of Trypanosoma can occur when the infected carrier tsetse fly bites the human body, leading to trypanosomiasis, which is also known as sleeping sickness. Transmission of Leishmania occurs when the female phlebotomine sand fly bite a human body causing Leishmaniasis that may be cutaneous, mucocutaneous or visceral (kala-azar), which may be manifested by skin lesions (ulcers), mucous membranes destruction in the mouth, nose and throat,

*Corresponding author: E-Mail: arafa_1998@yahoo.de, akmusa@ju.edu.sa ; Phone:+966-558775403 
irregular fever attacks, weight loss, spleen and liver enlargement, and anemia. Visceral Leishmaniasis may be fatal in some cases if left untreated [1]. Scrophulariaceae is one of the largest angiosperm families, distributed everywhere as ornamental or wild plants. It is composed of nearly 220 genera and 3,000 species [2]. It has been used traditionally in the treatment of wounds, eczema, ulcers, cancer, fistulae and goitres. Scrophulariaceae is rich in iridoid glycosides, which are cyclopentan-[c]-pyran monoterpenoids [3]. Scrophularia or figwort genus, is one of the largest genera distributed through mountainous regions and deserts. It comprises around 350 species which are a good source of iridoids, terpenoids, phenylpropanoids, flavonoids, phenolic acids and saponins [4]. They are hepatoprotective, antibacterial, anti-inflammatory, cardiovascular, protozoocidal, immuno-modulator, fungicidal, cytotoxic, molluscicidal, cytostatic and antitumor activities which may be due to the high content of iridoid glycosides [5]. Only limited biological screening has been reported for these plants [6]. However Atay et al [7] showed that, the secondary metabolites, i.e. flavonoids and iridoids of Ajuga laxmannii displays in vitro antiprotozoal activity and $S$. syriaca contains the same classes of metabolites. Thus, this study aimed to report the in vitro trypanocidal and leishmanicidal activities of the isolated metabolites from $S$. syriaca in order to discover natural antiprotozoal lead compounds from Saudi plants. The mechanism on Trypanosoma brucei glyceraldehyde-3-phosphate dehydrogenase (TbGAPDH) as well as the putative flexibility of TbGAPDH were studied.

\section{Materials and Methods}

\subsection{General Experimental Procedures}

UV spectra were recorded with a Hitachi 340 spectrophotometer (Tokyo, Japan). IR spectra were detected on a Nicolet 205 FTIR spectrometer connected to a Hewlett-Packard Color Pro Plotter (USA). NMR spectra were determined by a Varian Mercury (USA) $400 \mathrm{MHz}$ spectrometer at $400\left({ }^{1} \mathrm{H}\right)$ and 100 $\mathrm{MHz}\left({ }^{13} \mathrm{C}\right)$ in a DMSO- $d_{6}$ or $\mathrm{CD}_{3} \mathrm{OD}$ solution, and chemical shifts were expressed in $\delta(\mathrm{ppm})$ with reference to TMS and coupling constant $(J)$ in Hertz $(\mathrm{Hz})$. In addition, ${ }^{13} \mathrm{C}$ multiplicities were determined by a DEPTQ pulse sequence $\left(135^{\circ}\right)$. The EIMS spectra were measured by El/MS 502 mass spectrometer with a direct inlet system and operating at $70 \mathrm{eV}$. The ESI/MS spectra were measured by Bruker BioapexFTMS with electrospray ionisation (ESI; USA). Chromatographic separation was done on silica gel 60 ([0.063-0.200 mm]; Merck, Darmstadt, Germany), Sephadex LH-20 (Pharmacia, Uppsala, Sweden) and LiChroprep Diol (40-36 $\mu \mathrm{m})$, Supelco, Germany. Pre-coated TLC plates with silica gel $60 \mathrm{~F}_{254}(0.2 \mathrm{~mm}$, Merck, Darmstadt, Germany) were used. Developed chromatograms were first visualised by UV lamp $\left(254 \mathrm{~nm}, 365 \mathrm{~nm}\right.$; Cole-Parmar, USA), followed by spraying with $1 \%$ vanillin- $\mathrm{H}_{2} \mathrm{SO}_{4}$ and heating at 100 ${ }^{\circ} \mathrm{C}$. All mobile-phases were obtained from Scharlau, Chemie S.A. (Spain).

\subsection{Plant Material}

S. syriaca aerial parts were collected in May 2016 from the desert of Aljouf region, in the north of the Kingdom of Saudi Arabia (KSA). It was kindly identified by Mr. Hamdan Ogereef Al-Hassan, M.Sc. (Camel and Range Research Center), Aljouf, KSA. A voucher specimen was kept and deposited at the herbarium of the Pharmacognosy Department, College of Pharmacy, Jouf University.

\subsection{Extraction and Isolation}

The air-dried aerial parts of $S$. syriaca were ground $(\mathbf{2} \mathbf{~ k g})$ and exhaustively extracted with $70 \%$ ethanol $(10 \mathrm{~L} \times 3)$ after defatting with $n$-hexane $(\mathbf{2 2} \mathbf{g})$. The combined ethanolic extracts were evaporated at $45{ }^{\circ} \mathrm{C}$ in vacuo to afford $\mathbf{4 7} \mathrm{g}$ of dark green residue. The residue $(\mathbf{4 7} \mathrm{g})$ was suspended in $500 \mathrm{ml}$ distilled water and shaken with ethyl acetate 3 times to yield $\mathbf{1 7} \mathbf{g}$ residue. The EtOAc residue was subjected to VLC packed with silica gel stationary phase and eluted with $\mathrm{CH}_{2} \mathrm{Cl}_{2}-\mathrm{MeOH}(100: 0 \rightarrow 65: 35)$. The collected fractions (100 mL each) were monitored by TLC using ethyl acetate, methanol and water mixture in ratios of (100:12.5:13.5), and those showing similar chromatographic patterns were combined to give 5 major fractions (Frs.; I-V). Frs. II, III, and $V$ were selected for isolation of their contents by repeated flash chromatography, elution with $\mathrm{CH}_{2} \mathrm{Cl}_{2}$ : $\mathrm{MeOH}$ mixture. Fr. II afforded 3 sub-fractions (II $\mathrm{II}_{2}$, and $\mathrm{II}_{3}$ ). The sub-fraction $\mathrm{II}_{2}$ showed 2 major spots and, after successive $\mathrm{Si}$ gel $\mathrm{CC}$, resulted in the isolation of compounds $4(24 \mathrm{mg})$ and $7(33 \mathrm{mg})$. Fr. III was chromatographed on Si gel CC followed by 
Diol CC; LiChroprep ${ }^{\circledR}$ Diol $(40-63 \mu \mathrm{m})$ for liquid chromatography (Supelco), and further purification on Sephadex LH-20 to give compound 1 (17 mg), $2(15 \mathrm{mg})$ and $\mathbf{3}(20 \mathrm{mg})$. Compounds $5(15 \mathrm{mg}), \mathbf{6}(22$ $\mathrm{mg}$ ), and $\mathbf{8}(30 \mathrm{mg}$ ) were obtained from $F r . V$ (figure 1$)$.

\subsection{Anti-kinetoplastid Activity}

\subsubsection{Trypanosoma brucei Bloodstream Forms (BSF) In vitro}

Two strains of the bloodstream forms of Trypanosoma brucei were selected; the wild-type strain of T. brucei brucei (s427-WT) and T. brucei brucei (TbAT1-B48) that is derived from TbAT1-KO by exposure to pentamidine to cause more resistance to pentamidine and melamino phenyl arsenicals. Consequently, they have neither the TbAT1/P2 transporter nor the high-affinity pentamidine transporter [8], [9], see Table 1.

\subsubsection{Leishmania major and Leishmania mexicana}

L. major strain Friedlin $(\mathrm{LmjF})$ and L. mexicana (MNYC/BZ/62/M379) were propagated in essential medium (HOMEM) at $\mathrm{pH} 7.4$ and 10\% heat-inactivated foetal calf serum (FCS) using plastic flasks at a temperature of $25^{\circ} \mathrm{C}$. The resultant cultures were then passed through a fresh medium three times weekly, see Table 1.

\subsubsection{Trypanosoma brucei BSF In vitro}

HMI-9 medium is a standard culture that was utilised for the two strains and has $10 \%$ heat-activated FCS as well as $14 \mu \mathrm{l} /$ litre of $13.4 \mathrm{M} \beta$-mercapto ethanol with $\mathrm{pH}$ values adjusted to 7.4 using either $\mathrm{NaOH}$ or $\mathrm{HCl}[10]$. The medium was then sterilised by filtration inside a flow cabinet with $0.22 \mu \mathrm{m}$ pore sizes and Millipore Express PLUS membranes that provide ultra-fast filtration. Lastly, the parasites were incubated at a temperature of $37^{\circ} \mathrm{C}$ and a $5 \% \mathrm{CO}_{2}$ concentration and passed through vented flasks 3 times per a week.

\subsubsection{Conducting an Alamar Blue Assay to Determine the Sensitivity of Isolated Compounds}

The reagent Alamar Blue (resazurin) is commonly used as a cell metabolic function indicator. Resazurin (sodium salt), which is a non-fluorescent blue dye, was mixed with the cell culture that contains the drug solution in order to determine the sensitivity of African trypanosomes to the drug in vitro [11]. In case there are no toxic effects caused by the drug, the colour of the living cells changes from blue to red. The preparation of Alamar Blue involves the dissolving of $12.5 \mathrm{mg}$ of Sigma (resazurin sodium salt) into about $100 \mathrm{~mL}$ of phosphate-buffered saline (PBS) while adjusting the $\mathrm{pH}$ to around 7.4. The flow cabinet may then be used to sterilise the solution by means of filtration, and the filters used should have a membrane of $0.22 \mu \mathrm{m}$ (i.e., a Millipore Express PLUS membrane). The filtrate can be kept in the dark with a temperature of about $4^{\circ} \mathrm{C}$ for several weeks [12] or stored frozen for a long time. The resultant concentration of DMSO should not exceed 1\% since higher levels inhibit the growth of trypanosomes.

\subsubsection{Sensitivity of T. b. brucei, BSF, to Isolated Compounds Using Alamar Blue Assay}

The preparation of drugs' stocks was done at $200 \mu \mathrm{M}$. This was achieved through the dilution of $400 \mu \mathrm{M}$ stocks with the same amount of HMI-9 medium $+10 \%$ FCS in order to yield a 1:1 ratio of dilution. The resultant compound concentration in the first wells was $100 \mu \mathrm{M}$. Pipetting $200 \mu \mathrm{L}$ of 200 $\mu \mathrm{M}$ of different drugs into column 1 of a 96-well plate rows was then carried out. Each experiment was positively controlled using pentamidine, and the remaining wells were pipetted with $100 \mu \mathrm{L}$ of HMI-9 medium. $100 \mu \mathrm{L}$ of test drug was taken using a multichannel pipettor from column 1 then gently mixed with the medium in the column 2 wells, followed by $100 \mu \mathrm{L}$ taken from column 2 wells added to column 3 and so on. However, no drug solution was added to the last column well since the column is a drug-free control. The cells were counted and their density regulated at a concentration that was more appropriate $\left(2 \times 10^{5}\right.$ cells $\left./ \mathrm{mL}\right)$. This was then followed by an addition of $100 \mu \mathrm{L}$ of cells to every well in 
the plate at $1 \times 10^{5}$ cells $/ \mathrm{mL}$ as the final concentration of cells. The incubation of the plate was then done for 48 hours at $37{ }^{\circ} \mathrm{C}+5 \% \mathrm{CO}_{2}$. Next, $20 \mu \mathrm{L}$ of alamar Blue was added to every well, and the plate was incubated for another 24 hours. A fluorimeter was used to read the absorbance of the plate at the wavelengths of $590 \mathrm{~nm}$ for emission and $530 \mathrm{~nm}$ for excitation. The absorbance values were analyzed using the GraphPad Prism 5 software package to plot the data and obtain the $\mathrm{EC}_{50}$.

\subsubsection{The Alamar Blue Assay as an Indicator of Sensitivity to the Synthesized Compounds in L. major and L. mexicana}

The Alamar Blue assay for L. major promastigote sand L. mexicana had some similarities to the case of $T$. b. brucei. However, there were some differences, such as the use of the $7.4 \mathrm{pH}$ HOMEM medium and the $10 \%$ heat-inactivated FCS. Another distinctive factor was that the cells' final density in every well was $1 \times 10^{6}$ cells $/ \mathrm{mL}$. The incubation of the plate was for 72 hours at $25{ }^{\circ} \mathrm{C}+5 \% \mathrm{CO}_{2}$. Then, $20 \mu \mathrm{L}$ of Alamar Blue was added to every well, followed by an additional incubation for another 48 hours.

\subsection{Molecular Modelling Study}

Instruments: Dell Precision T3600 Workstation. Software: Molecular Operating Environment (MOE), package version 2016.08, was used in the docking experiments. The crystal structures of the TbGAPDH enzyme (PDB: 2X0N) was obtained from the Protein Data Bank [13, 14]. Docking of the co-crystallised ligand was performed to study the scoring energy (s), root mean and amino-acid interactions. Docking was performed using London dG force, and refinement of the results was done using force field energy. The compounds for docking were achieved via their 3D structure. Certain procedures were taken before docking, which included 3D protonation of the structures, running conformational analysis using a systemic search, selecting the least energetic conformer and applying the same docking protocol used with ligands. Amino-acid interactions and the hydrogen bond lengths were detected (Figure 2, Table 2).

\section{Results and Discussion}

\subsection{Phytochemical Studies}

Six iridoids and two flavonoids were isolated and elucidated from Scrophularia syriaca Benth. (Figure 1) by different spectroscopic techniques and by comparison with the reported literature. Compound 1 with the molecular formula of $\mathrm{C}_{21} \mathrm{H}_{32} \mathrm{O}_{14}$ was identified as 6-O- $\alpha-\mathrm{L}-$ rhamnopyranosylcatalpol [15]. Compound 2 with molecular formula $\mathrm{C}_{41} \mathrm{H}_{46} \mathrm{O}_{17}$ was elucidated as Scropolioside B [16]. Compound 3 of $\mathrm{C}_{32} \mathrm{H}_{40} \mathrm{O}_{16}$ was confirmed as gmelinoside L [15]. Compound $\mathbf{4}$ has the empirical formula of $\mathrm{C}_{17} \mathrm{H}_{26} \mathrm{O}_{11}$ and characterized as 8-O-acetylharpagide [17]. Compound 5 of $\mathrm{C}_{34} \mathrm{H}_{42} \mathrm{O}_{17}$ was established as scropolioside D [18]. Compound 6 was identified as scropolioside $\mathrm{D}_{2}$ and confirmed the molecular formula $\mathrm{C}_{36} \mathrm{H}_{44} \mathrm{O}_{18}$ [19]. Compound 7 and 8 were predicted as quercetin and kaempferol-3-O-rutinoside respectively [20]. It is noteworthy that all isolated compounds are reported for the first time from Scrophularia syriaca Benth. 

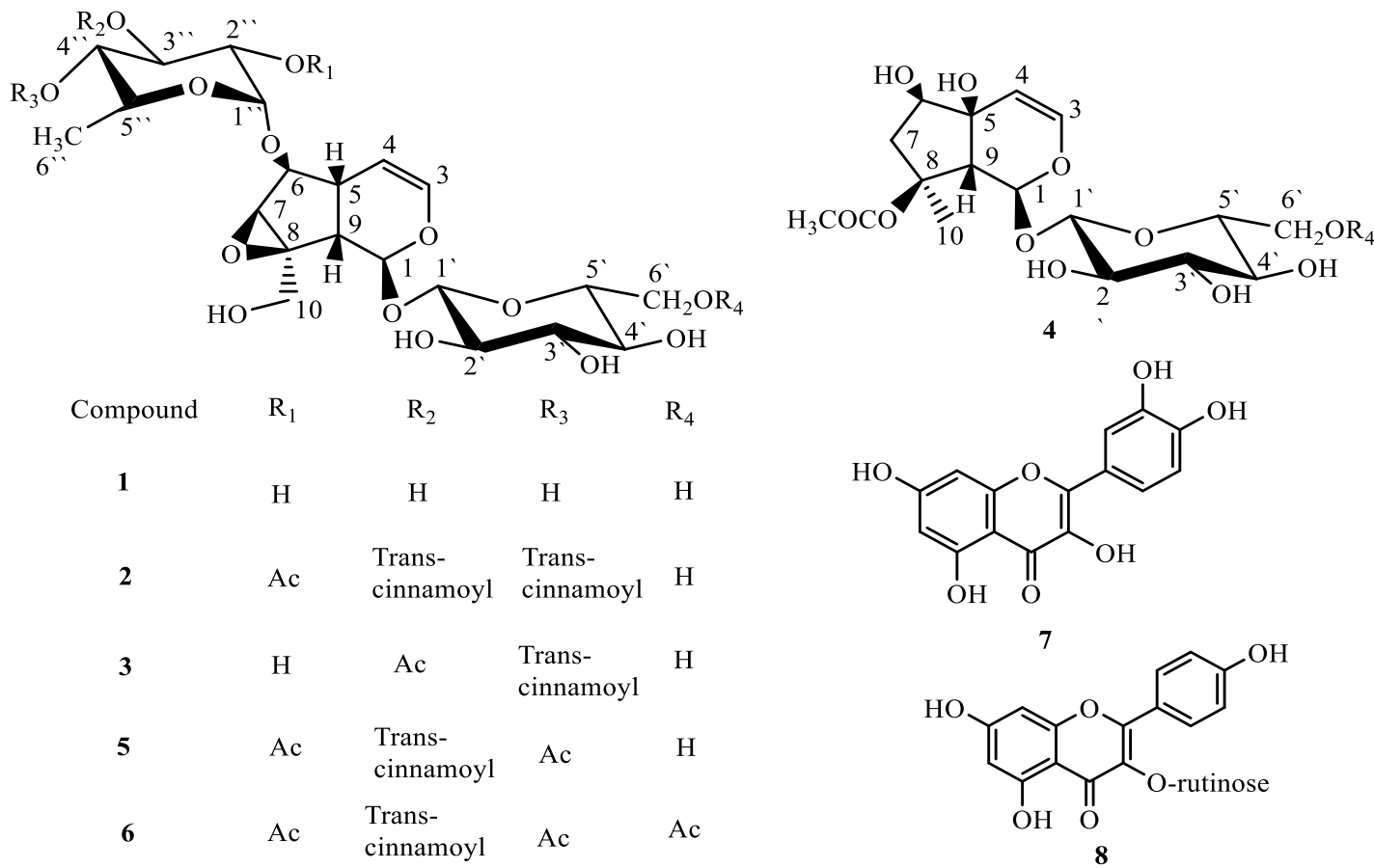<smiles>O=c1c(O)c(-c2ccc(O)c(O)c2)oc2cc(O)cc(O)c12</smiles><smiles>COc1c(-c2ccc(O)cc2)oc2cc(O)cc(O)c2c1=O</smiles>

Figure 1. Secondary metabolites isolated from $S$. syriaca

\subsection{Anti-kinetoplastid Activity}

Anti-protozoal activity of the individual metabolites was performed by Alamar Blue assay method [21]. Compound $\mathbf{2}$ was highly active with about $1 \mu \mathrm{M}$ of $\mathrm{EC}_{50}$, while compounds $\mathbf{5}, \mathbf{7}$ and $\mathbf{8}$ showed moderate activity against two strains of T. brucei brucei. Moreover, compounds $\mathbf{2}$ and $\mathbf{8}$ exhibited moderate activity against $L$. major and $L$. Mexicana compared to the positive control pentamidine (Table 1). Although significant resistance was displayed in $\mathrm{EC}_{50}$ for compound $\mathbf{5}$ by the B48 trypanosomes when compared to s427-WT, this compound showed less than two-folds resistance (compared to the 74-fold resistance shown for the control drug pentamidine). As such, there is no crossresistance for these compounds with the diamidine and melamino phenyl arsenical drugs, suggesting that the uptake mechanism of these compounds does not depend on any of the current transporters of $T$. brucei brucei, including TbAT1/P2 and HAPT1 (Table 1).

Table 1. Anti-kinetoplastid activity, $\mathrm{EC}_{50}$ values in $(\mu \mathrm{M})$

\begin{tabular}{|c|c|c|c|c|c|}
\hline Compounds & $\begin{array}{c}\text { T. brucei } \\
\text { brucei (s427- } \\
\text { WT), EC } \text { E }_{50} \\
(\mu \mathrm{M})\end{array}$ & 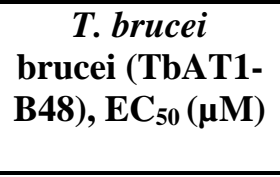 & RF & $\begin{array}{c}\text { L. major, } \\
\text { Promastigote } \\
\text { s, } \text { EC }_{50}(\mu \mathrm{M})\end{array}$ & $\begin{array}{c}\text { L. mexicana, } \\
\text { promastigotes, } \\
\mathrm{EC}_{50}(\mu \mathrm{M})\end{array}$ \\
\hline 1 & $>100$ & $>100$ & ND & $>100$ & $>100$ \\
\hline 2 & $1.75 \pm 0.05$ & $1.10 \pm 0.18$ & $0.63^{1}$ & $6.70 \pm 0.18$ & $8.34 \pm 1.70$ \\
\hline 3 & $>100$ & $>100$ & ND & $>100$ & $>100$ \\
\hline 4 & $>100$ & $>100$ & ND & $>100$ & $>100$ \\
\hline 5 & $43.18 \pm 1.77$ & $67.12 \pm 5.19$ & $1.55^{1}$ & $>100$ & $>100$ \\
\hline 6 & $>100$ & $>100$ & ND & $>100$ & $>100$ \\
\hline 7 & $35.36 \pm 8.42$ & $41.76 \pm 3.99$ & 1.18 & $>100$ & $>100$ \\
\hline 8 & $6.61 \pm 0.44$ & $5.34 \pm 0.52$ & 0.81 & $11.91 \pm 1.22$ & $10.02 \pm 1.68$ \\
\hline Pentamidine & $0.005 \pm 0.001$ & $0.37 \pm 0.01$ & $74^{2}$ & $4.34 \pm 0.17$ & $1.25 \pm 0.11$ \\
\hline
\end{tabular}

Average $\mathrm{EC}_{50}$ values for different compounds with standard errors. All results obtained using alamar blue assay and are given as averages in $\mu \mathrm{M}( \pm \mathrm{SEM})$. The results shown are the average of 3 independent values. ND $=$ not determined. Resistance Factor $(\mathrm{RF})=\mathrm{EC}_{50}(\mathrm{TbAT} 1-\mathrm{B} 48) / \mathrm{EC}_{50}(\mathrm{WT}) .{ }^{1} \mathrm{P}<0.05,{ }^{2} \mathrm{P}<0.001$ (Student $t$-test). 


\subsection{Molecular Docking Study}

The mechanism of action of the active compounds $(\mathbf{2}, \mathbf{5}, \mathbf{7}, \mathbf{8})$ was studied by molecular docking technique using the TbGAPDH enzyme [22]. The active compounds were docked onto the binding sites of TbGAPDH to confirm their ability as anti-trypanosomal agents. The highest activity of compound 2 was confirmed by the value of its score energy (S) of $-10.08 \mathrm{kcal} / \mathrm{mol}$ and the binding affinity to TbGAPDH (Figure 2, Table 2).

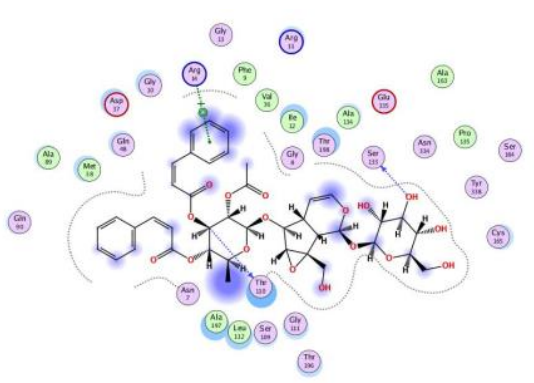

2a (Compound 2)

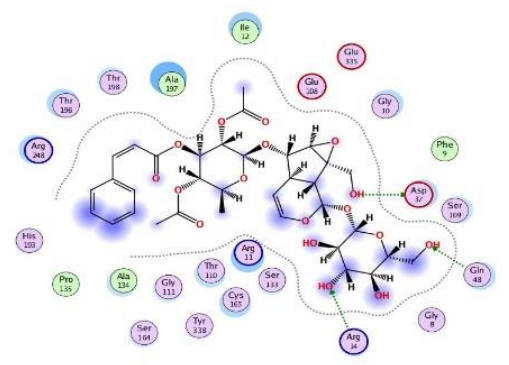

3a (Compound 5)

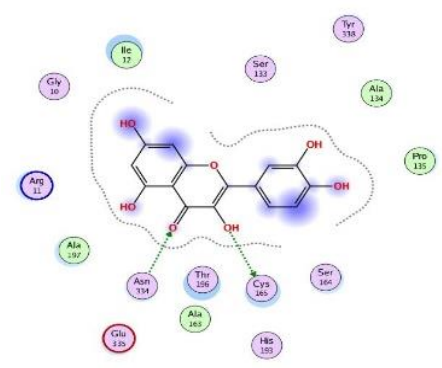

4a (Compound 7)

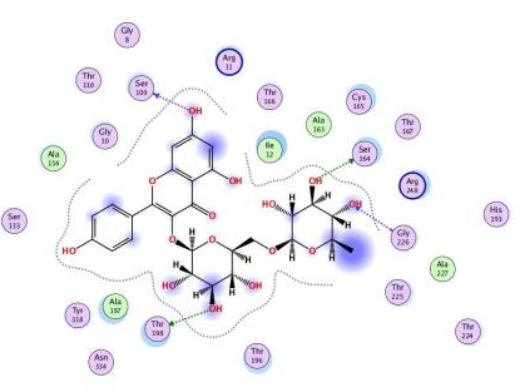

5a (Compound 8)

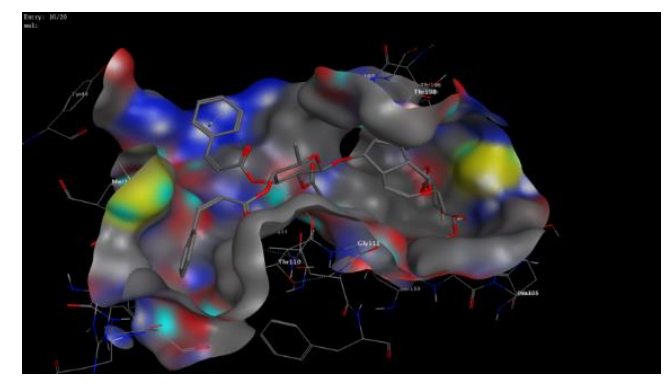

2b (Compound 2)
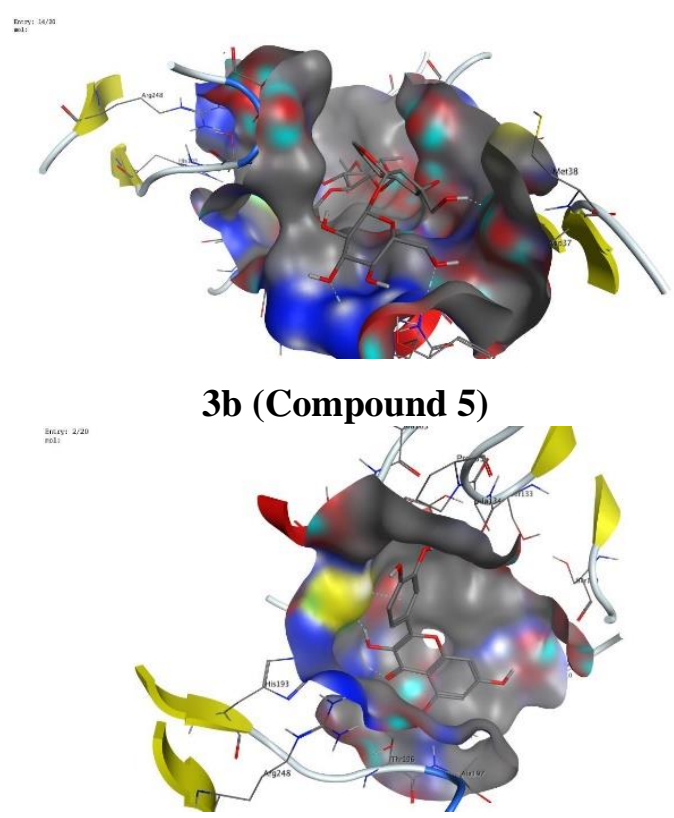

F 4b (Compound 7)

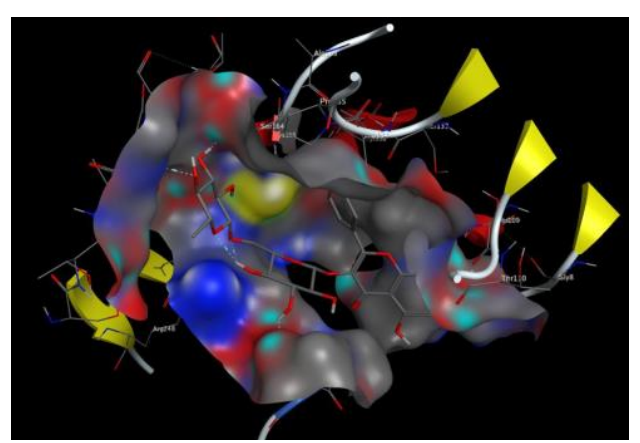

5b (Compound 8)

Figure 2. (a) $2 \mathrm{D}$ and (b) 3D interactions of active compounds $\mathbf{2 , 5 , 7}$ and $\mathbf{8}$ with the TbGAPDH enzyme 
Table 2. Molecular modelling data for compounds 2, 5, 7 and 8 with the TbGAPDH enzyme

\begin{tabular}{|c|c|c|c|c|}
\hline $\begin{array}{c}\text { Compound } \\
\text { No. }\end{array}$ & Affinity (Kcal/mol) & $\begin{array}{c}\text { Type of } \\
\text { interaction }\end{array}$ & $\begin{array}{l}\text { Receptor amino } \\
\text { acids' names } \\
\text { and numbers }\end{array}$ & $\begin{array}{c}\text { Functional } \\
\text { groups }\end{array}$ \\
\hline \multirow{2}{*}{2} & \multirow{2}{*}{-10.08} & \multirow{2}{*}{$\begin{array}{l}\text { Hydrogen bond } \\
\text { Hydrophobic } \\
\text { dipole-dipole } \\
\text { interaction }\end{array}$} & $\begin{array}{c}\text { Ser } 133 \\
\text { Arg } 14\end{array}$ & $\begin{array}{c}\mathrm{OH} \\
\text { aromatic }\end{array}$ \\
\hline & & & Thr 110 & $\mathrm{O}-\underline{\mathbf{C}}^{+\delta}$ \\
\hline 5 & -8.61 & Hydrogen bond & $\begin{array}{l}\text { Arg } 14 \\
\text { Gln } 48 \\
\text { Asp } 37\end{array}$ & $\mathrm{OH}$ \\
\hline 7 & -5.43 & Hydrogen bond & $\begin{array}{l}\text { Cys } 165 \\
\text { Asn } 334 \\
\text { Ser } 109\end{array}$ & $\begin{array}{c}\mathrm{OH} \\
\mathrm{C}=\mathrm{O}\end{array}$ \\
\hline 8 & -7.85 & Hydrogen bond & $\begin{array}{l}\text { Thr } 198 \\
\text { Gly } 226 \\
\text { Ser } 164\end{array}$ & $\mathrm{OH}$ \\
\hline
\end{tabular}

\section{Conclusion}

Per our knowledge, this is the first detailed study of bioactive compounds isolated from $S$. syriaca Benth. growing in Saudi Arabia. The isolated metabolites were elucidated by NMR, UV, IR and mass spectroscopy as well as by comparison with the literature data. Compound $\mathbf{2}$ exhibited high activity, particularly against $T$. brucei, while compounds $\mathbf{5}, \mathbf{7}$ and $\mathbf{8}$ showed mild to moderate antiprotozoal activity. For the compounds with trypanocidal effects, targeting of one validated drug target was investigated by docking the structures in the TbGAPDH active site, which identified various interaction bonds (hydrogen, hydrophobic, and dipole-dipole interaction) with a very low energy score $(-10.08$ to $-5.43 \mathrm{Kcal} / \mathrm{mol})$, which confirmed the strong affinity of the isolated compounds to this potential target enzyme.

\section{Conflict of Interest}

The authors declare no conflicts of interest.

\section{Supporting Information}

Supporting information accompanies this paper on http://www.acgpubs.org/journal/records-ofnatural-products

\section{ORCID $\odot$}

Abdulsalam A. M. Alkhaldi: 0000-0003-4170-0030

Arafa Musa: 0000-0003-0979-556X

Ehab M. Mostafa: 0000-0001-8841-9786

Elham Amin: 0000-0002-7190-3974

Harry P. De Koning: 0000-0002-9963-1827

\section{References}

[1] J. Bero, V. Hannaert, G. Chataigné, M.-F. Hérent and J. Quetin-Leclercq (2011). In vitro antitrypanosomal and antileishmanial activity of plants used in Benin in traditional medicine and bio-guided fractionation of the most active extract, J. Ethnopharmacol. 137(2), 998-1002.

[2] M. Rezaie-Tavirani, S. A. Mortazavi, M. Barzegar, S. H. Moghadamnia and M. B. Rezaee (2010). Study of anti cancer property of Scrophularia striata extract on the human astrocytoma cell line (1321), Iran. J. Pharm. Res. 9(4), 403-410. 
[3] S. U. Park, N. Il Park, Y. K. Kim, S. Y. Suh, S. H. Eom and S. Y. Lee (2009). Application of plant biotechnology in the medicinal plant, Rehmannia glutinosa Liboschitz, J. Med. Plants Res.,3(13), 12581263.

[4] A. Pasdaran and A. Hamedi (2017). The genus Scrophularia: a source of iridoids and terpenoids with a diverse biological activity, Pharm. Biol. 55(1), 2211-2233.

[5] J. de Santos Galíndez, Am. Díaz Lanza, and L. Fernandez Matellano (2002). Biologically active substances from the genus Scrophularia, Pharm. Biol. 40(1), pp. 45-59.

[6] M. Farheen and C. Ramesh (2015). Phytochemical evaluation and pharmacological screening of ethanolic bark extract of dolichondrone falcata for antihyperlipidemic activity in alloxan-induced diabetic albino wistar rats, World J. Pharm. Pharmaceut. Sci., 4(12), 819-840.

[7] I. Atay, H. Kirmizibekmez, M. Kaiser, G. Akaydin, E. Yesilada and D. Tasdemir (2016). Evaluation of in vitro antiprotozoal activity of Ajuga laxmannii and its secondary metabolites, Pharm. Biol. 54(9), 18081814.

[8] E. Matovu, M.L. Stewart, F. Geiser, R. Brun, P. Mäser, L. J. M. Wallace, R. J. Burchmore, J.C. K. Enyaru, M. P. Barrett, R. Kaminsky, T. Seebeck and H. P. de Koning (2003). Mechanisms of arsenical and diamidine uptake and resistance in Trypanosoma brucei, Eukaryot. Cell 2(5), 1003-1008.

[9] D. J. Bridges, M. K. Gould, B. Nerima, P. Mäser, R. J. S. Burchmore and H. P. De Koning (2007). Loss of the high affinity pentamidine transporter is responsible for high levels of cross-resistance between arsenical and diamidine drugs in African trypanosomes, Mol. Pharmacol.,71(4), 1098-1108.

[10] H. Hirumi and K. Hirumi (1989). Continuous cultivation of Trypanosoma brucei blood stream forms in a medium containing a low concentration of serum protein without feeder cell layers, J. Parasitol. 75(6), 985989.

[11] L. Fumarola, R. Spinelli and O. Brandonisio (2004). In vitro assays for evaluation of drug activity against Leishmania spp., Res. Microbiol. 155(4), 224-230.

[12] F. R. Opperdoes, E. Nohynkova, E. Van Schaftingen, A.-M. Lambeir, M. Veenhuis and J. Van Roy (1988). Demonstration of glycosomes (microbodies) in the Bodonid flagellate Trypanoplasma borelli (Protozoa, Kinetoplastida), Mol. Biochem. Parasitol. 30(2), 155-163.

[13] I. V. Ogungbe and W. N. Setzer (2016). The potential of secondary metabolites from plants as drugs or leads against protozoan neglected diseases-Part III: In-silico molecular docking investigations, Molecules 21(10), 1389/1-1389/48.

[14] E. Uliassi, G. Fiorani, R. L. Krauth-Siegel, C. Bergamini, R. Fato, G. Bianchini, J. C. Menéndez, M.T. Molina, E. López-Montero, F. Falchi, A. Cavalli, S. Gul, M. Kuzikov, B. Ellinger, G. Witt, C. B. Moraes, L. H. Freitas-Junior, C. Borsari, M.P. Costi and M.L Bolognesi (2017). Crassiflorone derivatives that inhibit Trypanosoma brucei glyceraldehyde-3-phosphate dehydrogenase (TbGAPDH) and Trypanosoma cruzi trypanothione reductase (TcTR) and display trypanocidal activity, Eur. J. Med. Chem. 141, 138-148.

[15] M. Hosny and J. P. N. Rosazza (1998). Gmelinosides A- L, Twelve acylated iridoid glycosides from Gmelina arborea, J. Nat. Prod. 61(6), 734-742.

[16] I. Calis, G.-A. Gross, T. Winkler and O. Sticher (1988). Isolation and structure elucidation of two highly acylated iridoid diglycosides from Scrophularia scopolii, Planta Med. 54(2), 168-170.

[17] A. Venditti, C. Frezza, M. Riccardelli, S. Foddai, M. Nicoletti, M. Serafini and A. Bianco (2016). Secondary metabolites from Scrophularia canina L., Nat. Prod. Res. 30(14), 1665-1669.

[18] I. Çalis, M. Zor, A. A. Basaran, A. D. Wright and O. Sticher (1993). Karsoside and scropolioside D, two new iridoid glycosides from Scrophularia ilwensis, J. Nat. Prod. 56(4), 606-609.

[19] B. Ahmed, A. J. Al-Rehaily, T. A. Al-Howiriny, K. A. El-Sayed and M. S. Ahmad (2003). ScropoliosideD2 and harpagoside-B: two new iridoid glycosides from Scrophularia deserti and their antidiabetic and antiinflammatory activity, Biol. Pharm. Bull. 26(4), 462-467.

[20] A. Musa, N. S. Al-muaikel and M. S. Abdel-Bakky (2016). Phytochemical and pharmacological evaluations of ethanolic extract of Bassia eriophora, Der Pharma Chem. 8(12), 169-178.

[21] B. Räz, M. Iten, Y. Grether-Bühler, R. Kaminsky and R. Brun (1997). The Alamar Blue® assay to determine drug sensitivity of African trypanosomes ( $T b$ rhodesiense and Tb gambiense) in vitro, Acta Trop. 68(2), 39-147.

[22] W.-W. Zhang, L.-I. McCall and G. Matlashewski (2013). Role of cytosolic glyceraldehyde-3-phosphate dehydrogenase in visceral organ infection by Leishmania donovani, Eukaryot. Cell 12(1), 70-77.

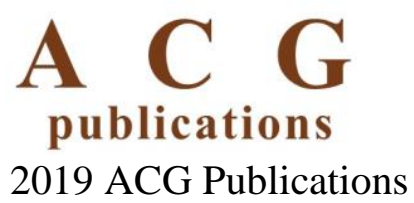

